\title{
О.А. погудин,
}

к.э.н., доцент кафедры теоретической экономики Рязанского государственного университета имени С.А. Есенина, г. Рязань, Россия, pogudinoa@mail.ru

\section{ПРИКЛАДНАЯ НАУКА В ВЕДОМСТВЕННЫХ ВУЗАХ: ЗАВЫШЕННЫЕ САМООЦЕНКИ И КРИТИЧЕСКИЕ РАЗМЫШЛЕНИЯ (НА ПРИМЕРЕ ВУЗОВ ФЕДЕРАЛЬНОЙ СЛУЖБЫ ИСПОЛНЕНИЯ НАКАЗАНИЙ РоссИИ)}

УДК 378.6, 001.3, 001.9

Погудин О.А. Прикладная наука в ведомственных вузах: завышенные самооценки и критические размышления (на примере вузов Федеральной службы исполнения наказаний России) (Рязанский государственный университет имени С.А. Есенина, улица Свободы, дом 46, г. Рязань, Россия, 390000)

1. Аннотация. В статье затрагивается актуальная, равно как и весьма широкая, для отечественных вузов тема,

I связанная с оценкой их научно-практической результативности. В центре авторского внимания отчетные

I внутриведомственные показатели, в погоне за которыми образовательные заведения Федеральной службы

исполнения наказаний искажают сущность прикладной научно-исследовательской деятельности, фактически

I занимаясь ее имитацией. Тем не менее, с их помощью данные вузы продолжают информировать общество

о собственной научной значимости и высоком инновационном потенциале, полностью реализуемом

в интересах органов и учреждений, исполняющих уголовные наказания. Критический анализ подобных

I самооценок, явно завышенных и в информативном отношении узконаправленных, отражает содержание

данной работы. Объективности суждений по поводу итогов научно-исследовательской деятельности вузов мог

I бы способствовать показатель социального и/или экономического эффекта, получаемого пенитенциарными

I учреждениями от их реального воплощения на практике.

I Ключевые слова: уголовно-исполнительная система, вузы ФСИН, Академия ФСИН, прикладные НИР в вузах

I ФСИН, имитация научной деятельности, профессорско-преподавательский состав вузов ФСИН, формальные

I показатели научно-практической результативности ППС, алгоритм реализации прикладных разработок,

I. социально-экономическая эффективность внедряемых инноваций.

DOI 10.22394/2410-132X-2018-4-3-198-209

I

Ц Цитирование публикации: Погудин О.А. (2018) Прикладная наука в ведомственных вузах: завышенные самооценки

I и критические размышления (на примере вузов Федеральной службы исполнения наказаний России) // Экономика

I) науки. Т. 4. № 3. С. 198-209.

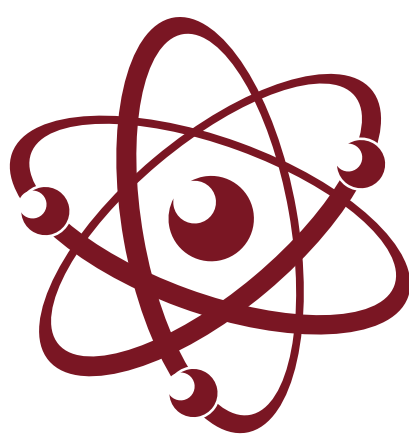

(C) О.А. Погудин, 2018 г.
Argumenta ponderantur, non numerantur Сила доказательств в их весомости, а не в количестве.

[Цит. по 1, с. 77]

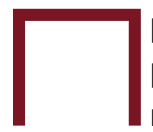

роцессы системной и институциональной динамики в сфере высшего образования диктуют необходимость повышения эффективности деятельности вузов, в том числе посредством проведения ими прикладных научных исследований, обеспечения их финансирования и коммерциализации полученных результатов [2-4]. Высшая школа в рамках программ своего развития становится частью экономической подсистемы государства, а сами вузы - полноправными рыночными структурами. 
Курс на активизацию образовательными учреждениями научно-исследовательских работ (НИР) и более тесное взаимодействие их с бизнесом, похоже, сформировался, хотя, по оценкам аналитиков, «вклад вузов в модернизацию промышленности и развитие производств нового технологического уровня остается незначительным» $[5$, с. 7]. Крупные научные проекты, инициированные предпринимательским сектором, с участием вузов широко не распространены [4]. Поэтому многие вопросы, касающиеся как реформы системы высшего образования и вузовской модели развития НИР, так и оценки инновационной активности университетов, до сих пор злободневны и открыты для широких дискуссий [4-11]. На этом фоне весьма значимыми представляются и те из них, которые связаны с оценкой результативности прикладной вузовской науки в системе ФСИН 1, безусловно, призванной способствовать обоснованным управленческим решениям и взвешенным практическим действиям по совершенствованию деятельности органов и учреждений уголовно-исполнительной системы (УИС) и их успешному реформированию.

Нацеленность государства на гуманизацию уголовно-исполнительной политики и реформу системы исполнения уголовных наказаний еще в начале XXI в. объективно обозначила потребность в исследованиях по уголовно-исполнительному праву, управлению персоналом, психологии и педагогике, организации социальной работы с осужденными, а также иным направлениям деятельности учреждений ФСИН - производственно-хозяйственной, по обеспечению режима содержания и безопасности осужденных, повышению эффективности исправительных воздействий на них. Как отмечал в те годы профессор А. Буданов, это «сделало насущным комплексное изучение постсоветской тюремной системы в ее единстве и всей сложности определяющих

1 Федеральная служба исполнения наказаний России (ФСИН) - федеральный орган исполнительной власти, подведомственный Минюсту РФ, осуществляющий правоприменительные функции, функции по контролю и надзору в сфере исполнения уголовных наказаний в отношении осужденных (здесь и далее прим. автора). ее действенность экономических, социальных, правовых, психологических и иных условий, факторов и компонентов» $[12$, с. 206]. Согласно Концепции развития уголовно-исполнительной системы до 2020 года, активное использование научного потенциала образовательных организаций высшего образования ФСИН выступает одним из ключевых условий повышения эффективности управления УИС [13].

Целью статьи является выяснение того, насколько корректными и объективными представляются достижения прикладной вузовской науки, реализуемой согласно отчетам по заказу профильных Управлений центрального аппарата ФСИН России и соответствующих Управлений в регионах, регулярно планируемой и по вузовским самооценкам обладающей весомой практической значимостью для учреждений, исполняющих уголовные наказания. Мы хотели бы убедиться в том, какую в действительности роль играет сегодня выпускаемая штатным профессорско-преподавательским составом (ППС) научная продукция с точки зрения так необходимого обществу совершенствования деятельности российских пенитенциарных структур. Новизна статьи видится автору в ее тематике, поскольку попытка переосмыслить результативность осуществляемых высшими учебными заведениями ФСИН прикладных НИР, выходя за рамки официально устоявшейся по этому поводу точки зрения, предпринимается едва ли не впервые за весь период реформы высшего образования.

Изучая способности любого коллектива продуктивно осуществлять научные изыскания, принято отталкиваться от количественных и качественных характеристик научно-исследовательского потенциала его субъектов. Раскрывающая их содержание статистика по вузам ФСИН, вне всяких сомнений, весьма внушительна. По официальной версии в научной работе участвует отнюдь немалое число лиц, обладающих как учеными степенями и званиями, так и иными общественно и научно значимыми достижениями. В частности, в Академии ФСИН России (далее - академии) в научной работе принимают участие 72 доктора наук, 250 кандидатов наук, из них - 59 профессоров, 147 доцентов... [14]. 
В Самарском юридическом институте из 150 научно-педагогических работников 22 имеют ученую степень доктора наук, 104 кандидата наук; в их числе 10 профессоров и 33 доцента [15]. По итогам проведенного Воронежским институтом ФСИН России самообследования, научно-исследовательской деятельностью занимается 100\% ППС на всех кафедрах института [16]. Между тем, приведенные цифры, по нашему глубокому убеждению, не следует воспринимать буквально. Большинство лиц из заявленных в качестве исследователей не являются полноценными сотрудниками вузов (закончили службу в УИС, работают на условиях совместительства, замещают должности ППС на неполную ставку и т.п.), либо на деле не привлекаются к выполнению закрепленных за кафедрами прикладных НИР.

Похожая ситуация, свойственная, впрочем, и иным учебным заведениям, хорошо известна специалистам, анализирующим проблемы отрасли. С одной стороны, по свидетельству профессора Е. Трубниковой, «при увольнении остепененного сотрудника вуз не всегда теряет в показателях. При прохождении аккредитации, мониторинга эффективности и иных процедур контроля в документы вуза могут быть включены данные уволившихся докторов наук, тем самым шансы вуза на получение положительного вердикта от регулирующих структур увеличиваются» [17, с. 99]. С другой - по меткому выражению А. Гусева, наука в отечественных вузах (что особенно справедливо в отношении вузов ФСИН) «осуществляется лишь отдельными представителями ППС в режиме любительства, когда те принимают участие в научной работе на условиях совместительства при наличии полной учебной нагрузки» [4]. Согласно приведенным им оценкам, в каждом вузе, осуществляющем научную деятельность, менее 100 человек было занято исследованиями и разработками на постоянной основе 2 [там же].

О том, кто такие отдельные представители ППС, любящие НИР как «надомный труд

2 По статистике Минобрнауки РФ, удельный вес лиц из числа ППС, ведущих научную деятельность официально и инициативно, варьировался по профильным группам вузов от 22 до 36\% [4]. в приватной обстановке» [8, с. 140], нетрудно заключить из многочисленных работ известного в научно-экспертных кругах профессора Е. Балацкого. Речь преимущественно идет о кандидатах наук и доцентах, которые «в силу многоступенчатого процесса деградации академических статусов были низведены до уровня университетских пролетариев» [6, с. 158], а также рядовых преподавателях, «из-за возникшего в вузах «управленческого синдрома перекладывания обязанностей сверху вниз», превратившихся в универсальных специалистов с огромным числом разнородных и ... несовместимых компетенций: от способности находить, лоббировать, заключать и выполнять договора на проведение НИР» [7, с. 143] до «... рекрутинга абитуриентов в течение круглогодичных профориентационных компаний» $[8$, с. 140]. Безусловно, установка на непосредственное участие преподавательского состава в научных исследованиях и реальных бизнес-проектах становится для многих из них аксиомой, хотя растущий объем формальных требований, налагаемых на персонал кафедр, приводит к тому, что «добросовестное выполнение им всех контрактных требований является скорее исключением, чем правилом» ${ }^{3}$ [9, с. 130]. В то же время, «разделение всего контингента научных кадров на администраторов (хозяйственников) и собственно исследователей, ... когда последние попадают в разряд социальных изгоев без прав и рычагов давления на администрацию» [18, с. 121], чрезвычайно обостряет проблему отчуждения как формы отношения «рядового» преподавателя к своему непосредственному труду. По справедливому замечанию профессора О. Мамедова, «уподобившийся песчинке, ... униженный, нигде и ни для кого незначимый, принуждаемый жить по выдумкам ... мелких внутривузовских администраторов ..., неуважаемый никем, да и собой тоже, преподаватель в полной мере ощутил сегодня высшую

3 ППС вузов ФСИН в рамках своего функционала подвержен стольким несвойственным академическим работникам дополнительным служебным обязательствам, что это оказывается за пределами разумного, а нередко и за пределами физических возможностей людей. 
меру отчуждения - бездомность, бессмысленность и диктуемость извне своего профессионального существования 4 [19, с. 11$]$.

Исходя из сказанного выше и учитывая, что «институт кандидатской степени стал в стране поистине массовым, прекратив выполнять функцию селекции научных кадров высшей квалификации» [6, с. 162], а фальсификация диссертаций в академии является делом обыденным [20], тезис о проведении высокого научного уровня фундаментальных и прикладных исследований в ведомственных учреждениях высшего образования [14] со стороны упомянутых категорий работников представляется совершенно безосновательным. В этой связи становится очевидным вывод первый. Вузовские «мощности» научного производства в интересах совершенствования пенитенциарной практики вопреки официальным заверениям задействуются далеко не полностью. Формальная констатация высоких академических статусов преподавательского персонала в вузах ФСИН отнюдь не гарантия ни полноты его участия в прикладных НИР, ни достигаемых при этом высоких научных результатов.

Что же касается практической значимости научных и научно-методических разработок, то и здесь на передний план выходят количественные показатели, формально наиболее выигрышные, но объективно в информативном отношении явно узконаправленные. Так, «удельный вес научно-исследовательских разработок, выполненных в академии по заданиям ведомства и заявкам территориальных органов УИС, ... составляет более 90\% от общего объема НИР. В 2013/14 учебном году сотрудниками академии в целях научного и научно-методического обеспечения деятельности практических органов и вузов ФСИН России было подготовлено 184 научных продукта и учебно-методических материала» [21,

4 Исключительно точная позиция проф. О. Мамедова в том, что ««отчужденный» преподаватель ненавидит свой труд и место своей работы, еще недавно входившие в его личный мир» [там же] отражает губительное следствие тех социально-трудовых отношений, которые сложились сегодня в образовательных заведениях уголовно-исполнительного ведомства. с. 4]. А в соответствии «с запросами государственных и региональных органов власти более 60 предложений, из них большая часть касалась федерального законодательства» [21, с. 5] (табл. 7). Оговариваясь, что «не каждая новая научная разработка доходит до практического применения», один из вузовских функционеров указывал на «определенную в этом отношении динамику» $[22$, с. 16]. По его словам в 2011/12 учебном году исполнители получили 123 акта внедрения результатов НИР в образовательный процесс и практическую деятельность органов и учреждений УИС, в 2012/13 - 149, в 2013/14 учебном году - 194. В адрес академии поступило 6 отзывов об использовании ее предложений при подготовке законопроектов, направленных на регулирование деятельности УИС. 20 разработок получили положительную оценку со стороны структурных подразделений (профильных Управлений) ФСИН России и рекомендованы к их использованию на местах. Вузом «заключены договоры о сотрудничестве в сфере НИР и внедрения ее результатов с 76 территориальными органами УИС» [22, c. 16-17].

Похожие результаты достигнуты в Самарском юридическом институте ФСИН России [15]. В 2016 г. в деятельность практических подразделений УИС внедрен 51 результат НИР, выполненных в Воронежском институте ФСИН России, при этом, по заключению авторов самообследования института, «отмечается возрастание как общего количества работ, так и доли прикладных исследований, выполняемых по заявкам практических подразделений ведомства» [16]. Согласно официальным данным, почти половина исследований в Вологодском институте права и экономики ФСИН России также осуществляется по заявкам территориальных органов УИС.

Проведенный в 2016 г. анализ наличия и использования в работе территориальных органов результатов НИР ведомственных образовательных и научных организаций, показал, что произведенная ими научная продукция внедрялась в деятельность подразделений УИС 1475 раз. При этом 428 внедренных разработок приходилось на долю академии 


\section{Итоги участия профессорско-преподавательского состава и научных сотрудников Академии ФСИН России в нормотворческой и прикладной научно-исследовательской работе в 2011-2017 гr.}

\begin{tabular}{|c|c|c|c|c|c|c|c|}
\hline \multirow{2}{*}{ Показатель } & \multicolumn{7}{|c|}{ Год } \\
\hline & 2011 & 2012 & 2013 & 2014 & 2015 & 2016 & 2017 \\
\hline $\begin{array}{l}\text { Количество предложений в федеральное } \\
\text { законодательство }\end{array}$ & 66 & 9 & 15 & 33 & 22 & 21 & 20 \\
\hline $\begin{array}{l}\text { Количество предложений в нормативные пра- } \\
\text { вовые акты Минюста России и ФСИН России } \\
\text { по совершенствованию законодательства } \\
\text { и нормотворческой деятельности }\end{array}$ & - & 16 & 5 & 11 & 10 & 9 & 7 \\
\hline $\begin{array}{l}\text { Количество предложений в региональное } \\
\text { законодательство }\end{array}$ & 4 & 5 & 2 & 1 & 1 & 1 & 3 \\
\hline $\begin{array}{l}\text { Количество предложений в международные } \\
\text { правовые акты и стандарты }\end{array}$ & - & - & - & 1 & - & 1 & - \\
\hline $\begin{array}{l}\text { Количество полученных актов о внедрении } \\
\text { результатов НИР в практическую деятель- } \\
\text { ность органов и учреждений УИС }\end{array}$ & $\begin{array}{c}\text { нет } \\
\text { данных }\end{array}$ & 91 & 103 & 178 & 442 & 458 & 700 \\
\hline
\end{tabular}

Источник: составлено автором на основании [14]

и 39 - на долю ее Псковского филиала. Из представленной на сайте головного вуза отчетности видно, что его коллективом в 2017 г. подготовлено 248 научных продуктов (в том числе 66 разработок, адресованных практическим работникам), получено 700 актов о внедрении в практическую деятельность органов и учреждений УИС 5 [14].

Трансформируемые в академии в балльно-рейтинговые единицы количественные итоги прикладных НИР с растущими вверх показателями «актовнедряемости» (табл. 7) позволили ранжировать по степени научной значимости и кафедры вуза, и их сотрудников [23], способствуя тем самым формированию прагматичного взгляда на успешного преподавателя, умеющего достигать нужных результатов. Однако такая процедура, во-первых, вряд ли серьезно противостоит «эффекту неразличимости

5 Сведения о том, какие новые знания и новые решения содержатся в подобных разработках и предложениях, в [14] отсутствуют. Однако подчеркивается, что «возросшее число методических и практических разработок ... и расширение географии внедрения результатов проводимых исследований» признаются основными значимыми результатами научной деятельности вуза [там же]. кадров»6 [18, с. 124], а, во-вторых, игнорирует ответы на очевидно более важные вопросы. Какую, собственно, для себя пользу извлекают те структуры ФСИН, которые производят на свет подобные акты? Насколько объективны эти документы?

Осмысливая содержание научно-инновационной деятельности вуза, ряд авторов увязывает ее не только с «созданием новаций, но и обеспечением их трансфера, полезности и экономической результативности... Желательным является завершение трансфера получением экономического результата в виде дохода, прибыли, системы показателей рентабельности..., производительности,

6 Данный эффект наблюдается в ситуации, когда при сравнении представителей ППС на предмет того, кто из них лучше, затраты на проведение тщательной экспертизы нередко не оправдываются сугубо субъективными выводами, из нее вытекающими [18, с. 124]. В ведомственных вузах этот эффект нужно трактовать шире. Например, когда действительно успешные в научном плане преподаватели по собственной инициативе переводятся на новое место службы, переходят, увольняясь из УИС, в иные сферы деятельности с более высокой капитализацией профессиональных навыков, а вузовский менеджмент, который, казалось бы, должен быть заинтересован в данных специалистах, зачастую содействует такого рода миграции. 
фондо- и ресурсоотдачи ... Результат внедрения реципиентом оценивается в виде сопоставления положительной и отрицательной полезности новшества. Положительная разница полезностей новации расценивается как ее эффективность» [3, с. 41]. «Эффективная деятельность вуза как создателя новых знаний и новых стоимостей может рассматриваться только в системном единстве высокого ... уровня проводимых разработок и отлаженных механизмов включения полученных знаний в хозяйственный оборот» [2, с. 59]. «Эффективность результатов научно-исследовательского процесса вуза может быть оценена по общеэкономическим показателям роста в соответствующей отрасли, по экономическим показателям ... организаций, внедривших соответствующие новации» $[24$, с. 54]. «... Приоритетом должно стать создание ... социальных и технологических инноваций, их внедрение в практику и оценка их эффективности» $[11$, с. 180]. «Сегодня только критерий работоспособности создаваемых алгоритмов, ... конструкций и агрегатов может дать надежную основу правильности научных доктрин» [25, с. 133]. В конечном счете, укажем и на то, что «основатель инноватики Й. Шумпетер, определял прибыль предпринимателя как результат практической реализации новшества ...» [10, с. 241].

Подытоживая сказанное, отметим следующее. Результаты НИР востребованы, если они материализуются во вновь созданной стоимости, а в более общем случае - непосредственно улучшают работу предприятий и организаций, активно использующих конкретные новшества. Отсюда вытекает вывод второй. Если генерируемые вузами социальные и технологические инновации содействуют совершенствованию разносторонней пенитенциарной практики, то получаемый подразделениями ФСИН социальный и/или экономический эффект (как отражение реальной выгоды от их сотрудничества с вузом), собственно, и призван явиться критерием результативности прикладных ведомственных разработок. По крайней мере, той их части, где подобный эффект возможно оценить.

Представляется, что столь высокий уровень научного обеспечения УИС со стороны подведомственных вузов не может не отразиться на итогах повседневной деятельности исправительных учреждений, в частности, по регулированию порядка, условий исполнения и отбывания уголовных наказаний, определению средств исправления осужденных, охране их законных интересов либо привлечению к производительному труду и содействию в ресоциализации. Однако на деле этого не происходит. Как отмечается в средствах массовой информации, тюрьма является больным местом правоохранительной системы, она стремительно деградирует и продолжает существовать в парадигме середины прошлого века [26]. Какие-либо позитивные тенденции, например, в экономике и производственной сфере УИС, качестве занятости осужденных, размерах погашаемых ими исков либо уровне постпенитенциарного рецидива фактически не наблюдаются [27]. Оказался финансово несостоятельным первоначальный вариант Концепции развития УИС до 2020 года [13], а многие идеи (отнюдь не бесспорные), преподносимые в виде продолжения пенитенциарной реформы, генерируются не столько вузовскими учеными, сколько чиновниками ФСИН без должного обоснования и широкого обсуждения со стороны профессионалов и общества. Кроме того, весомое для УИС значение приобретают сегодня правозащитные организации, анализирующие ее «болевые точки» и обладающие реальной возможностью сообщить о них властным структурам [28]. К сказанному лишь добавим, что из 48 подготовленных ППС академии в 20132014 гг. предложений в адрес государственных органов власти (табл. 7), лишь восьмая их часть получила отражение в соответствующих законопроектах [22]. Сколько же их «осталось» в самих законах - неизвестно.

Зададимся вполне резонными вопросами, откуда такой «расцвет науки» в пенитенциарной системе, как оказалось во многом консервативной к любым возможным переменам, четверть века находящейся в стадии перманентного реформирования и до сих пор мало чем в организационно-структурном отношении отличающейся от советской исправительно-трудовой системы 1980-х гг.? Неужели 
статистика научно-методической помощи, оказываемой ППС работникам учреждений УИС и законодательным органам, действительно отражает спрос на производимую вузами ФСИН научную продукцию, особенно, когда повторяющиеся скандалы, связанные с неправомерными действиями персонала в отношении осужденных [20], давно стали своеобразной визитной карточкой уголовно-исполнительного ведомства? Какие же собственно прорывные идеи и социальные инновации внедряются в практику отечественных исправительных заведений, если еще относительно недавно (в сентябре 2009 г.) предыдущий Директор ФСИН России на научно-практической конференции в Минюсте указывал на неразвитость прикладной составляющей науки и ее существование по принципу «сама по себе» [29, с. 3]. Где проявляются социально-экономические эффекты выполненных разработок (например, в сфере социогуманитарных знаний), в чем они заключаются, кто и как их задействует? Отсутствие четких и убедительных ответов на поставленные вопросы со стороны пенитенциарных вузов как субъектов инновационной деятельности порождает вывод о сомнительности ее содержания и качества результатов, и, как минимум, формализме, связанном с их внедрением. Выходит, что сознательно завышая научную самооценку (в интересах пропаганды собственного имени, популяризации «бренда»), образовательные структуры ФСИН, скорее всего, отрываются от реальности и не могут предложить практическим органам ничего полезного. Так называемые «теоретические пузыри кабинетных исследований» [25, с. 128] вряд ли способны вызвать у них значительный интерес, а напоминание практикам известных истин слабо увязывается с научным познанием.

Поиск ответа на вопрос, а нужно ли пенитенциарной системе (в контексте ее нелестной характеристики) от входящих в нее вузов вообще что-то полезное и значимое, отсылает нас к пониманию тех специфических особенностей организации и реализации НИР, которые давно в них сложились. Формально являясь заказчиком и потребителем инноваций, органы и учреждения УИС на деле лишь подстраиваются под возможности и отдельные интересы находящихся в жестких условиях вузовского администрирования кафедральных коллективов, которые, вынуждены инициировать предложения (порой, с красивыми и наукообразными формулировками), сводящиеся к решению ими якобы насущных для практиков задач. Другими словами, вуз, позиционирующий себя в качестве исследовательской единицы, реализует научно-исследовательские мероприятия, исходящие от кафедр как его структурных составляющих, но никак не от заказчиков - конкретных уголовно-исполнительных учреждений и стоящих над ними территориальных органов управления УИС в регионах. Разумеется, официально считается, что заявка на выполнение НИР исходит именно от практиков и формируется с учетом их «производственных» потребностей. Тем самым, если в гражданском университете сотрудник, следуя установленному финансовому нормативу 151,28 тыс. руб./год на одного научно-педагогического работника по линии НИР в периферийном вузе [30]), «должен самостоятельно добывать коммерческие заказы и сам же их выполнять» [6, с. 168], то в вузах пенитенциарных - самостоятельно находить заказы внутриведомственные, впоследствии отчитываясь об их выполнении так называемыми актами О внедрении.

Безусловно, практическая ценность такого рода заказов может никогда не проявиться. И не только по причине возможного отторжения учреждениями УИС всего нового либо нежелания с их стороны усмотреть перспективность конкретных социально-гуманитарных новшеств, но и в силу неоправдавшихся ожиданий по поводу содержательной части предлагаемых к внедрению рекомендаций, методик, алгоритмов и т.п. Кроме того, несмотря на определенное взаимопонимание между элементами внутриведомственной системы: «заказчик - вузовский исполнитель - потребитель НИР» среднестатистический преподаватель с ученой степенью заведомо не является в ней определяющим звеном. В понимании своих контрагентов он не относятся к числу экспертов, имеющих право на авторитетное высказывание, принятие «судьбоносных» решений либо вынесение окончательного 
вердикта по спорным вопросам [25]. Экспертами (не считая, видимо, правозащитников) признаются сегодня должностные лица в административно-управленческой иерархии территориального органа или соответствующего подразделения в Управлении центрального аппарата ФСИН, оценивающие предложенные им вузовские разработки (аналитический отчет, методические рекомендации) преимущественно с позиций соответствия их тематики оформленной заявке или бесспорности с их точки зрения сформулированных в них положений. Эти люди и определяют, выдать авторам НИР акт приемки или нет.

Ускорить принятие нужного сотруднику вуза решения призвано так называемое авторское сопровождение разработки. Его истинная цель не мотивация исследователя к разрешению возможного «противоречия» между теорией и практикой и, тем более, не забота о жизнеспособности выдвигаемых им научных доктрин, а совершенно иная. Налаживание и усиление неформальных коммуникаций, установление дружественных межличностных отношений между названными сторонами позволяет каждой из них преследовать свои собственные интересы по принципу взаимовыгодных бартерных сделок. Фактически речь идет о «двунаправленном извлечении ренты, когда обе стороны ... получают выигрыш от наличия неформальных взаимоотношений» [31, с. 42]. Поэтому наделенный весомыми должностными полномочиями практик часто выступает в роли соавтора рецензируемого им «инновационного» продукта, является номинальным участником учебного процесса в вузе, обязательным (нередко почетным) представителем на научно-практических конференциях и семинарах, включается в число председателей Государственной аттестационной комиссии. Его пожелания (пожелания курируемых им региональных ведомственных структур) вполне могут быть учтены в работе приемной комиссии учебного заведения.

Что же касается представителя ППС, то полученный им акт внедрения - основание для предоставления вузовским администраторам формализованной отчетности о собственной эффективности. Ее демонстрация независимо от содержательных результатов НИР и вопреки «эффекту неразличимости кадров», является залогом успешного продвижения по научно-рейтинговой шкале $[9,23]$, а то и приобретения в связи с этим определенных бонусов. Поэтому наличие или отсутствие у кафедры упомянутых актов может сводиться лишь к одному - наличию либо отсутствию у ее руководителей (или преподавателей) соответствующих связей с потенциальными «заказчиками и потребителями НИР». Причем, чем активней реализуется именно такая (скрытая) функция авторского сопровождения, тем большие потери несет каждый конкретный индивидуум при отклонении от нее. В этом смысле обладание данным документом говорит не о реальных научно-практических достижениях конкретного сотрудника вузовской кафедры, а всего лишь о плодотворности затраченных им усилий ради его приобретения.

Примечательно, что описанный выше алгоритм реализации прикладных разработок в вузах ФСИН находит свое объяснение в концепции старых рынков, когда доминирующим фактором успеха в «старой» науке становится «активная маркетинговая позиция исследователя, базирующаяся на его коммуникационных навыках и соответствующих обширных социальных связях. В этом случае можно заставить целые коллективы работать на себя, раздуть в экономике брендов из мухи слона и занять лидирующее положение в отрасли» [18, с. 126].

Таким образом, для ведомственного вуза акт внедрения - один из формальных параметров его внешней статусной оценки (своего рода, деловой репутации, бренда), а с позиций экономической теории - нужный его руководству рыночный сигнал, посредством которого оно популяризирует достоинства выпускников через оценку «научности» преподавательского состава, который их готовил. Для практических органов ФСИН, выдаваемый ими акт - есть ни к чему не обязывающий документ, выпадающий из сквозной системы внутриведомственного планирования и контроля. Отсутствие подобной информации в ежегодных итоговых отчетах О заседаниях Коллегии ФСИН России или игнорирование в ведомственных приказах такого направления деятельности подразделений УИС 
как внедрение вузовской научной продукции [32] - лишь яркое тому подтверждение. Отсюда вполне логичен вывод четвертый и основной. Не «некоторые руководители учреждений и органов УИС» [21, с. 16], а их большинство (наряду с самим ППС) не рассматривают всерьез внедрение НИР в деятельность подчиненных служб и подразделений. Стало быть, никакого значения для них вузовские прикладные разработки не представляют. Подобно тому как результаты научного труда пока не находят широкого применения в экономике и обществе, а вузовская наука не является авангардом сектора исследований и разработок в России [4, 5], так и вузовские прикладные НИР априори не могут быть востребованы УИС, по крайней мере так, как это красочно преподносится на их уровне.

Итоговое заключение сформулируем в виде двух резюмирующих тезисов, тесно сопрягающихся с позициями аналитиков, на работы которых мы неоднократно ссылались.

Во-первых, «логистический поворот» в науке (в терминологии М. Беляевой [8]), когда логистика «начинает играть роль «примы» в научном производстве» [8, с. 141], фактически совершился в науке ведомственной и, в частности, прикладной пенитенциарной. Если для гражданских вузов основная опасность подобного поворота кроется в преимущественной «проверке компетентности ученого на рынке ... и способности зарабатывать деньги на исследовательских заказах» [6, с. 168], то для вузов ФСИН - в симуляции их исполнения, абсолютном «замещении содержательной деятельности «работой на показатель»» [9, с. 125]. В последнем случае «истинное научное творчество превращается в формальное производство «псевдонаучного спама»» ${ }^{7}$

7 Об этом говорит почти полное отсутствие отражающих сущность кафедральных разработок публикаций в научных и научно-практических журналах, включая журналы, издаваемые вузами ФСИН. Последние, в свою очередь, часто вообще не заслуживают внимания со стороны авторитетного научного сообщества. Они же являются «героями» «Диссернета»и отнесены им к категории журналов с грубыми и многочисленными нарушениями [20].
[8, с. 141] в угоду даже не коммерческим, а сугубо административным оппортунистическим интересам.

Во-вторых, наряду с полным отсутствием «неденежной академической ренты» в отношении преподавательского труда (творчество, признание, свобода, репутация) и существенным ограничением «ренты антирисковой» (стабильность занятости) [6, с. 153], такого рода «логистический поворот» является главным фактором, обуславливающим ни что иное, как активную имитацию научной деятельности в ведомственных вузах. Поэтому в данных условиях нет оснований считать ее результативной и значимой для органов и учреждений, исполняющих уголовные наказания. Для повышения объективности в оценке результативности НИР следовало бы, согласно вынесенному в заголовок статьи эпиграфу, не уповать лишь на ее формальные количественные параметры, а прибегать к более весомым аргументам. И таким из них, из-за невозможности вузами иметь прямые доходы от потребителей научной продукции в рамках одного ведомства, могла бы стать величина социально-экономического эффекта, получаемого учреждениями УИС От реализации вузовских разработок на практике. Сегодня она в подавляющем большинстве случаев почти минимальна, а усиление административного давления на ППС способно лишь усилить его отчуждение и не сделает эту величину принципиально иной. Оставляя за рамками статьи возможные предложения по решению обозначенной проблемы (хотя, их основную идею нетрудно усмотреть из приведенного выше текста), констатируем лишь следующее: мифотворчество в прикладной «фсиновской» науке продолжается. И это немаловажное обстоятельство не способствует укреплению авторитета ФСИН в глазах российского общества.

Автор выражает искреннюю признательность двум анонимным рецензентам за ценные замечания в адрес первого варианта рукописи, позволившие ему существенно улучшить ее окончательное содержание. 


\section{ЛИТЕРАТУРА}

1. Вайнмахер А.М., Шмерлинг Д.С. (2015) Стратегия научных публикаций в России // Экономическая наука современной России. № 1. С. 77-82.

2. Владыка М.В. (2009) Коммерциализация результатов научно-технической деятельности вузов: цели, формы, проблемы // Университетское управление: практика и анализ. № 5. С. 54-63.

3. Сафонова К.И., Ерышева С.А. (2009) Научно-инновационная деятельность вуза: цели, задачи, управленческие механизмы // Университетское управление: практика и анализ. № 6. С. 38-43.

4. Гусев А.Б. (2012) Современный профиль вузовской науки в России и перспективы его изменения // Капитал страны, 15.10.2012. http://kapitalrus.ru/articles/article/216596

5. Куракова Н.Г., Зинов В.Г., Озорнин А.В. (2015) Драйверы экономического развития страны: университетская наука или промышленные компании? // Инновации. № 4 С. 7-12.

6. Балацкий Е.В. (2014) Истощение академической ренты // Мир России. № 3. С. 150-174.

7. Балацкий Е.В. (2015) Управленческие парадоксы реформ в университетском секторе // Журнал Новой экономической ассоциации. № 2 (26). C. 124-149.

8. Беляева М.А. (2015) Почему научно-исследовательская работа преподавателя вуза - это «хромая лошадь» современной науки? // Образование и наука. № 3. С. 130-143.

9. Курбатова М.В., Каган Е.С. (2016) Оппортунизм преподавателей вузов как способ приспособления к усилению внешнего контроля деятельности // JOURNAL OF INSTITUTIONAL STUDIES (Журнал институциональных исследований). Т. 8. № 3. С. 116-136.

10. Волков А.Т. (2017) Показатели оценки инновационной активности и сложности их определения // Экономика науки. Т. 3. № 4. С. 240-249.

11. Романов Е.В. (2017) Без модернизации высшего образования у России нет будущего // ЭКО. № 2. C. 173-188.

12. Буданов А.В. (2002) Роль пенитенциарной науки в правовом государстве // Материалы науч. практ. конф. «Роль органов юстиции в правовом государстве». М.: Российская правовая академия. С. 205-209.

13. Распоряжение Правительства Российской Федерации от 14 октября 2010 г. № 1772-р (в ред. распоряжений Правительства РФ от 31.05.2012 г. № 874-р, от 23.09.2015 г. № 1877-р) (2010) Концепция развития уголовно-исполнительной системы Российской Федерации до 2020 года / Техэксперт. http://docs.cntd.ru/document/902241566.

14. Академия ФСИН России - научно-исследовательская деятельность (2018) / Официальный сайт ФСИН России. http://www.apu.fsin.su/area/ scientific_activities/index.php.

15. Тимофеева Е.А. (2015) Научные достижения Самарского юридического института ФСИН России в 2014 году // Уголовно-исполнительная система: право, экономика, управление. № 2. С. 3-5.

16. Отчет о результатах самообследования образовательной организации (2017) / Федеральное казенное образовательное учреждение высшего образования Воронежский институт Федеральной службы исполнения наказаний (ФКОУ ВО Воронежский институт ФСИН России). http://xn blam.xn - hlakkl.xn - plai/upload/territory/Vi/ obrazovanie/doc/samoobsledovanie_za_2016.pdf.

17. Трубникова Е.И. (2016) Паттерны поведения в преподавательской среде // Высшее образование в России. № 1 (197). С. 95-104.

18. Балацкий Е.В. (2010) Кризис социальных наук в свете концепции старых рынков // Социологический журнал. № 2. С. 118-133.

19. Мамедов О. (2015) Феномен «Готского» отчуждения // TERRA ECONOMICUS. T. 13. № 4. C. 6-16.

20. Ростовцев А., Мелихова Л. (2018) Тюремные науки: от фальшивых диссертаций до пыток // Троицкий вариант-Наука, 31.07.2018. (№ 259). С. 11. https://trv-science.ru/2018/07/31/tyuremnyenauki-fsin-v-dissernete.

21. Крымов А.А. (2014) На передовой образования УИС России // Ведомости уголовно-исполнительной системы. № 11. С. 2-7. http://or.fsin.su/ upload/territory/Or/PDF/vedomosti/PDF/2014/ Ved\%20UIS 11_2014.pdf.

22. Рыжов Р.С. $(20 \overline{1} 4)$ Роль Академии ФСИН России в научном обеспечении деятельности учреждений и органов уголовно-исполнительной системы // Ведомости уголовно-исполнительной системы. № 11. C. 14-17. http://or.fsin.su/upload/ territory/Or/PDF/vedomosti/PDF/2014/Ved\%20 UIS_11_2014.pdf.

23. Мониторинг научной деятельности кафедр Академии ФСИН России и Псковского филиала Академии ФСИН России в 2017 году (2018) / ФСИН. Аналитический обзор. Рязань. http://www.apu. fsin.su/territory/Apu/area/scientific_activities/ nid_2017.pdf.

24. Альгина М.В., Синельников В.С. (2007) Измерение эффективности процесса научных исследований и исследовательских разработок вуза // Университетское управление: практика и анализ. № 5. С. 52-55.

25. Балацкий Е.В. (2009) «Теоретические пузыри» на рынке научных исследований // Общество и экономика. № 4-5. С. 124-140. http://nonerg-econ. ru/filedata/article_file/10-teoreticheskie-puzyri-oiepdf_453.pdf. 
26. Романова О., Козлов А. (2017) Страна отмотала сто лет лагерей. Краткий анамнез российской уголовно-исполнительной системы // Новая газета. № 54, 24.05.2017. https://www.novayagazeta. ru/articles/2017/05/24/72542-strana-otmotalasto-let-lagerey.

27. Погудин О.А. (2017) Производство и труд в пенитенциарной системе: динамика кризиса и неопределенность будущего // ЭКО. № 12. C. 99-112.

28. Киюцина О. (2016) «ФСИН: Финансирование уходит на «лучшую жизнь» тюремной бюрократии» / Доклад Института проблем современного общества (ИПСО). http://i-pso.ru/2016/12/06/01-8.

29. Научно практическая конференция по вопросам реформирования уголовно исполнительной системы. Выступление директора Федеральной службы исполнения наказаний А.А. Реймера (2009) // Служу закону. Газета Вологодского института права и экономики ФСИН России. Вып. № 5 (19). С. 2-3. http://xn - hlakkl.xn plai/territory/Vipe/images/press_sluzhba/gazeta/ nomera/5(19)2009.pdf.

30. Мониторинг эффективности деятельности организаций высшего образования (2018) / Министерство образования и науки РФ. http://indicators. miccedu.ru/monitoring.

31. Трубникова Е.И. (2016) Захват регулирования образовательной среды: анализ отдельных аспектов // Высшее образование в России. № 11 (206). С. 38-46.

32. Приказ ФСИН России от 14.06.2012 г. № 325 (2012) Об установлении оценки деятельности территориальных органов Федеральной службы исполнения наказаний при инспектированиях // Ведомости уголовно-исполнительной системы. 2012. № 11; № 12. https://ukrfkod.ru/laws/ Prikaz-FSIN-Rossii-ot-14.06.2012-N-325.

\section{REFERENCES}

1. Vainmakher A.M., Shmerling D.S. (2015) Strategy of scientific publications in Russia // Economic science of modern Russia. № 1. P. 77-82.

2. Vladyka M.V. (2009) Commercialization of results of scientific and technological activities of higher education: goals, forms, problems // University Management: Practice and Analysis. № 5. P. 54-63.

3. Safonova K.I., Erysheva S.A. (2009) Universities research and innovation activities: goals, objectives, management arrangements // University Management: Practice and Analysis. № 6. P. 38-43.

4. Gusev A.B. (2012) Modern profile of Higher School science in Russia and Prospects of its change. Capital of country, 15.10.2012. http://kapital-rus.ru/articles/article/216596.

5. Kurakova N.G., Zinov V.G., Ozornin A.V. (2015) Drivers of economic development: university science or industrial companies? // Innovations. № 4. P. 7-12.

6. Balatsky E.V. (2014) Depletion of Academic Rents // World of Russia. № 3. P. 150-174.

7. Balatsky E.V. (2015) Managerial Paradoxes of Reform University Sector // Journal of the New Economic Association. № 2 (26). P. 124-149.

8. Belyaeva M.A. (2015) Why scientific research of a lecturer is the «lame horse» of modern science? // Education and science. № 3. P. 130-143.

9. Kurbatova M.V., Kagan E.S. (2016) Opportunism of university professors as a way of adapting to increase of external supervision of the activities // Journal of Institutional studies. V. 8. № 3. P. 116-136.

10. Volkov A.T. (2017) Indicators for assessing innovation activity and the complexity of their definition // Economics of science. V. 3. № 4. P. 240-249.

11. Romanov E.V. (2017) Russia has no future without modernization of higher education // ECO. № 2. P. 173-188.

12. Budanov A.V. (2002) The role of the penitentiary science in legal state // Proc. the Scientific Conference «The Role of justice in the constitutional state». Moscow: Rossijskaja pravovaja akademija. P. 205-209.

13. The decree of the Government of the Russian Federation dated 14.10.2010 № 1772-r (as amended by RF Government Decree № 1877-r dated 23.09.2015) (2010) Concept of development of Penal system of the Russian Federation until 2020 / Techexpert. http://docs.cntd.ru/document/902241566.

14. The Academy of the Federal Penitentiary Service's of Russia - research activities (2018) / Website of FSIN. http://www.apu.fsin.su/area/scientific_activities/index.php.

15. Timofeeva E.A. (2015) Scientific achievements of Samara juridical Institute of FPS of Russia in 2014 // Penal system: law, economics, management. № 2. P. 3-5.

16. Report on the results of self-examination of the educational organization (2017) / Russian Federation Security Guard Service Federal Academy of Voronezh Institute of the Federal Penal Service. http://xn - blam.xn - hlakkl.xn - plai/upload/ territory/Vi/obrazovanie/doc/samoobsledovanie_ za_2016.pdf.

17. Trubnikova E.I. (2016) Behavior Patterns in the System of Higher Education // Higher Education in Russia. № 1 (197). P. 95-104. 
18. Balatskiy E.V. (2010) The Crisis of Social Sciences in the Light of the Concept of Old Markets // Journal of sociology. № 2. P. 118-133.

19. Mamedov O. (2015) The Phenomenon of the «Gothic» Alienation // TERRA ECONOMICUS. V. 13. № 4. P. 6-16.

20. Rostovtsev A., Melihova L. (2018) Prison sciences: from false theses to torture // Troitsky variant - science, 31.07.2018. (№ 259). P.11. https://trv-science. ru/2018/07/31/tyuremnye-nauki-fsin-v-dissernete.

21. Krymov A.A. (2014) At the forefront of education in the penal system of Russia // Statements of Penal system. № 11. P. 2-7. http://or.fsin.su/upload/ territory/Or/PDF/vedomosti/PDF/2014/Ved\%20 UIS_11_2014.pdf.

22. Ryzhov R.S. (2014) The role of the Academy of the FPS of Russia in scientific support of activity of the authorities and corrective institutions // Statements of Penal system. № 11. P. 14-17. http://or.fsin.su/ upload/territory/Or/PDF/vedomosti/PDF/2014/ Ved\%20UIS_11_2014.pdf.

23. Monitoring of the scientific activity of the departments of the Academy of the Federal Penal Service of Russia and the Pskov affiliated institution of the Academy of the Federal Penal Service of Russia in 2017 (2018) / FSIN. Analytical review. Ryazan. http://www.apu.fsin.su/territory/Apu/area/scientific_activities/nid_2017.pdf.

24. Algina M. V., Sinelnikov V.S. (2007) Measurement of the effectiveness of the university's research process and research developments // University management: Practice and Analysis. № 5. P. 52-55.

25. Balatsky E.V. (2009) «Theoretical bubbles» at the market of scientific researches // Society and economy. № 4-5. P. 124-140. http://nonerg-econ.ru/ filedata/article_file/10-teoreticheskie-puzyri-oiepdf_453.pdf.
26. Romanova O. Kozlov A. (2017) the country clocked up a hundred years of camps. Brief anamnesis of the Russian penitentiary system // New Newspaper. № 54, 24.05.2017. https://www.novayagazeta.ru/articles/2017/05/24/72542-strana-otmotalasto-let-lagerey.

27. Pogudin O. (2017) Labor and Production in the Penal System: Crisis Dynamics and Uncertainty of the Future // ECO. № 12. P. 99-112.

28. Kiyutsina O. (2016) FPS: Funding goes for a «better life» of prison bureaucracy. Report of the Institute of Modern Society's problems. http://i-pso. ru/2016/12/06/01-8.

29. Scientific-practical conference on the reform of the Penal system. FPS head A. Reimer's speech (2009) // Serve the law. Journal of the Vologda Institute of Law and Economics of the Russian Federal Penal Service. № 5 (19). P. 2-3. http://xn - hlakkl. xn - plai/territory/Vipe/images/press_sluzhba/ gazeta/nomera/5(19)2009.pdf.

30. Monitoring the effectiveness of Higher Education. Website of the Ministry of Education and Science of the Russian Federation (2018). http://indicators. miccedu.ru/monitoring.

31. Trubnikova E.I. (2016) Regulatory capture of the higher education area: the analysis of some aspect // Higher education in Russia. № 11 (206). P. 38-46.

32. Order of the Federal Penal Service of Russia dated 14.06.2012 № 325 (2012) On the establishment of an assessment of the activities of territorial agencies of the Federal Service for the execution of punishments during inspections // Statements of Penal system. 2012. № 11; № 12. https://ukrfkod.ru/laws/Prikaz-FSIN-Rossii-ot-14.06.2012-N-325.

UDC 378.6, 001.3, 001.9

1 Pogudin O.A. Applied science in the departmental universities: Inflated self-esteem and critical thinking I In an example of Federal Penitentiary Service's universities of Russia) (Ryazan State University named for I S. Yesenin, Str. Svobody, 46, Ryazan, Russia, 390000)

- Abstract. Article addresses relevant as well as extremely broad topic for local universities related to the assessment I of their scientific and practical efficiency. In the center of the author's attention, there are reportable formal I quantitative indicators in chase of which the educational institutions of the Federal Penitentiary Service's (FPS of I Russia) distort the essence of applied scientific research, in fact, imitating it. Nevertheless, with their help these I universities continue informing the public about their own scientific importance and high innovative potential, fully I realized for the benefit of institutions which carry out penal sanctions. A critical analysis of such self-assessments I obviously overstated and narrowly focused in terms of information reflects the content of this article. The indicator of I social and / or economic effect obtained by the penal establishments from their actual implementation in practice I could contribute to the objectivity of judgments about the results of the universities' applied scientific research.

Keywords: penal system, universities of FPS, the Academy of the FPS, applied scientific research in the universities of FPS, imitation of the scientific activity, universities of FPS's teaching staff, formal indicators of the teaching staff's scientific and practical effectiveness, algorithm for implementing applied developments, socio-economic efficiency of I the innovation being implemented. 